\section{Procedural improvisation to prevent guidewire kinking in Griggs percutaneous tracheostomy without bronchoscopic guidance}

Sir,

We read with great interest the case report titled, "Inadvertent migration of guidewire into Murphy's eye of endotracheal tube during percutaneous dilatational tracheostomy" by Binita et al. ${ }^{[1]}$

We wish to highlight procedural modification we are doing in our Intensive Care Unit to tackle such inadvertent complication.

We agree with the authors that migration of guidewire into the Murphy's eye of endotracheal tube during percutaneous tracheostomy without bronchoscopic guidance is a rare complication, which we also encounter rarely but we follow a procedural improvisation by ensuring free movement of guidewire back and forth at each step, thus ensuring proper placement of guidewire.

In case of guidewire inside the Murphy's eye, there will be kinking of guidewire after dilatation with metal/plastic dilator, thus the free back and forth movement of the guidewire will not be appreciated, or in other words, if the free movement of guidewire not felt, a possible diagnosis of guidewire kinking is made.

In our case series of 300 cases of percutaneous tracheostomy without bronchoscopic guidance, we had 18 cases where guidewire got kinked, hampering the free back and forth movement during the procedure. ${ }^{[2]}$ We removed the guidewire and again a fresh puncture of trachea done to complete the procedure.

Few possible reasons for guidewire kinking are such as cephalic migration or migration into the Murphy's eye or false passage can be easily diagnosed and rectified by 
ensuring the free back and forth movement of guidewire during each step of the procedure.

In our case series, we have highlighted two important steps: First one by withdrawing of the endotracheal tube with inflated cuff while monitoring expired tidal volume on ventilator and the second one by ensuring free mobility of guidewire during each step of the procedure, thereby ensuring a safe placement of the tracheostomy tube in trachea.

\section{Financial support and sponsorship}

Nil.

\section{Conflicts of interest}

There are no conflicts of interest.

Saroj Kumar Pattnaik, Banambar Ray Department of Critical Care Medicine, Apollo Hospital, Bhubaneswar - 751 005, Odisha, India

Correspondence: Dr. Saroj Kumar Pattnaik, Department of Critical Care Medicine, Apollo Hospital, Bhubaneswar, Odisha, India. E-mail: drsarojpatnaik@gmail.com

\section{References}

1. Panigrahi B, Samaddar DP, Kumar T. Inadvertent migration of guidewire into Murphy's eye of endotracheal tube during percutaneous dilatational tracheostomy. Indian J Crit Care Med 2016;20:188-90.

2. Pattnaik SK, Ray B, Sinha S. Griggs percutaneous tracheostomy without bronchoscopic guidance is a safe method: A case series of 300 patients in a tertiary care intensive care unit. Indian J Crit Care Med 2014;18:778-82.

This is an open access article distributed under the terms of the Creative Commons Attribution-NonCommercial-ShareAlike 3.0 License, which allows others to remix, tweak, and build upon the work non-commercially, as long as the author is credited and the new creations are licensed under the identical terms.

\begin{tabular}{|l|l|}
\hline \multicolumn{2}{|c|}{ Access this article online } \\
\hline Quick Response Code: & Website: \\
& www.ijccm.org \\
\cline { 2 - 2 } & DOI: $10.4103 / 0972-5229.183901$ \\
\hline
\end{tabular}

How to cite this article: Pattnaik SK, Ray B. Procedural improvisation to prevent guidewire kinking in Griggs percutaneous tracheostomy without bronchoscopic guidance. Indian J Crit Care Med 2016;20:378-9. 